\title{
Effect of centralization on complex surgical care: A population-based case study of radical cystectomy
}

D. Robert Siemens, MD ${ }^{1,2}$; Kash Visram, MD ${ }^{1}$; Xuejiao Wei, $\mathrm{MD}^{3}$; Christopher Booth, $\mathrm{MD}^{2,3,4}$

${ }^{1}$ Department of Urology, Queen's University, Kingston, ON, Canada; ${ }^{2}$ Department of Oncology, Queen's University, Kingston, ON, Canada; ${ }^{3}$ Department of Public Health Sciences, Queen's University, Kingston, ON, Canada; ${ }^{4}$ Division of Cancer Care and Epidemiology, Queen's University Cancer Research Institute, Kingston, ON, Canada

Cite as: Can Urol Assoc J 2019 November 5; Epub ahead of print. http://dx.doi.org/10.5489/cuaj.5998

Published online November 5, 2019

$* * *$

\section{Abstract}

Introduction: We sought to determine whether non-mandated or passive centralization of radical cystectomy $(\mathrm{RC})$ to higher-volume centers leads to enhanced processes-of-care and outcomes.

Methods: This is a population-based, retrospective cohort study that used the Ontario Cancer Registry (OCR) to identify all incident patients who underwent RC from 1994-2013. Electronic records of treatment were linked to OCR; pathology records were obtained for all cases and reviewed by a team of trained data abstractors. The primary objective was to describe annual provider RC volumes. Secondary objectives included investigating process and outcome measures.

Results: For the 5574 patients identified, the mean annual surgeon volume and hospital volume of RC during 1994-2008 was 4.5 (95\% confidence interval [CI] 4.4-4.7) and 12.2 (95\% CI 11.8-12.5), respectively. From 2009-2013, these volumes significantly increased to 6.8 (95\% CI 6.5-7. 1) and 16.4 (95\% CI 15.8-16.9). Process variables improved over time, including the use of neoadjuvant chemotherapy. Over the study period, there was a substantial improvement in cancer-specific survival (CSS): hazard ratio (HR) 0.60 (95\% CI 0.53-0.67) for 2009-2013. During the most recent era, there was still evidence of a provider volume effect on both process measures and CSS.

Conclusions: There has been recent passive centralization of $\mathrm{RC}$ to higher-volume providers in the province of Ontario with measurable improvements in processes of quality care. Although centralization was also associated with improvement in CSS, in the most recent era, there continues to be low-volume providers with a residual volume-outcome effect. 


\section{Introduction}

Centralization of complex surgical care is now central in the contemporary global conversation to improve outcomes, particularly in surgical oncology. The rationale has been founded by cumulative evidence that high volume providers have better outcomes across multiple cancer sites ${ }^{(1,2)}$. Despite concerns with the evidence-base supporting this volume effect, strong associations with optimized processes-of-care in alignment with improved early and late outcomes would seem to satisfy both face and construct validity of the concept ${ }^{(3,4)}$. To capitalize on this knowledge, mandated centralization of care to high volume centers and surgeons or benchmarking key processes-of-care for lower-volume providers could be considered. Although there is increasing experience internationally ${ }^{(5,6)}$, criticism of mandated centralization of surgical care remains particularly regarding the potential to decrease access to care ${ }^{(7,8)}$. Accordingly, widespread adoption across cancer sites has been halting.

Radical cystectomy (RC) for bladder cancer in as an interesting model to explore these concepts in the North American context. First, RC is a relatively common and complex oncological surgical procedure and population studies of routine surgical care have suggested sub-optimal results compared to high volume centers of excellence ${ }^{(2,9,10)}$. Second, ideal outcomes for invasive bladder cancer are dependent on a multi-disciplinary approach. Third, several perioperative processes-of-care have been well delineated, including utilization of perioperative chemotherapy which can lead to a modest but definitive improvement in outcomes ${ }^{(2,11)}$. Despite some experience with mandated centralization in other jurisdictions, RC in North America has not been the subject of such focus from health authorities notwithstanding several calls from key stakeholders ${ }^{(12)}$. We hypothesized that some degree of passive centralization of $\mathrm{RC}$ will have occurred in recent years due to rising awareness of the volume-outcomes phenomenon within the urologic oncology community. Furthermore, we hypothesized that any passive centralization in a large population would be associated with measurable changes in processes-of-care and improvements in oncological outcomes.

\section{Methods}

This is a population-based retrospective cohort study that used the Ontario Cancer Registry (OCR) to identify all incident patients in Ontario who underwent RC between 1994-2013 (13). The primary objectives of this current study were to identify trends indicating passive centralisation of RC in the contemporary era and to evaluate any associations between hospital and surgeon RC volumes and the processes of care that are linked to early and late outcomes. In order to determine if any passive centralization coincided with potential detrimental patientcentered effects, we looked at global wait times and patient distance travelled to surgical care. Finally, we theorized that any degree of centralization of surgical care might dampen well described provider volume effects on outcomes.

The OCR is a population-based registry that captures diagnostic and demographic information on $98 \%$ of all incident cases of cancer diagnosed in Ontario ${ }^{(14) .}$ Stage of disease was 
not routinely available from the existing data source hence pathology records were obtained for all cases and reviewed by a team of trained data abstractors with periodic quality audits performed by the study investigators. Hospital care and surgical intervention data was obtained from the Canadian Institute for Health Information ${ }^{(15)}$ and chemotherapy utilization information was obtained using treatment records from Ontario regional cancer centres and physician billing records as previously described ${ }^{13}$. These datasets were linked using unique encoded identifiers and analyzed at ICES.

Comorbidity was assessed using the Charlson Comorbidity Index and socioeconomic status information was obtained as previously described ${ }^{(16)}$. Surgical wait times were measured from time of diagnosis documented within OCR to the time of their RC and distance travelled was aerial distance between residence and hospital location. The number of cystectomies performed at each hospital per year was derived from the overall study population. A volume level for each hospital and surgeon was derived as previously described using the mean annual number of cystectomies over a five-year study period ${ }^{(2)}$. Although there are no validated volume benchmarks for RC, we assigned high volume providers as $>6.2$ cases per year for surgeons and $>20$ cases per year for hospitals based on previous work in a historical Ontario cohort (2).

To compare proportions between study groups the Chi-square test was used. From the OCR, survival data was determined from the date of surgery using the Kaplan-Meier technique, and comparisons within groups were made using the log-rank test. Cox-proportional hazards regression models were used to assess the association between patient, disease, and treatment related factors on OS and CSS. All analyses were performed using SAS, version 9.4 (SAS institute, Cary, NC). The study was approved by the Research Ethics Board of Queen's University. This study was designed, analyzed, and reported in accordance with the STROBE (Strengthening the Reporting of Observational Studies in Epidemiology) statement ${ }^{(17)}$.

\section{Results}

Between 1994-2013, 5574 patients were identified having undergone RC for bladder cancer in Ontario. Characteristics of the study population can be found in Table 1. Cases were divided into four eras spanning the 20 years of the study, with a stable number of $\mathrm{RC}$ being performed in the two most recent eras (2004-2013). As depicted in Figure 1A, over the entire study period there has been a marginal increase in the median number of cases done by surgeons but a substantial increase in the volume at the hospital level. The mean annual surgeon volume and hospital volume of RC during 1994-2008 was 4.5 (95\% confidence interval [CI] 4.4-4.7) and 12.2 (95\% CI 11.8-12.5), respectively. In the more contemporary era, these volumes significantly increased to $6.8(95 \%$ CI 6.5-7.1) $(\mathrm{p}<0.01)$ and $16.4(95 \%$ CI 15.8-16.9) $(\mathrm{p}<0.01)$. Furthermore, there has been an increasing trend in the proportion of $\mathrm{RC}$ completed by higher volume surgeons $(>6.2$ cases) and at higher volume centers ( $>20$ cases) over the entire study period (Figure 1B) $(\mathrm{p}<0.001$ for both surgeon and center volume). In the most recent years, greater than $40 \%$ of $\mathrm{RC}$ were done by higher volume providers. 
After excluding cases with $<$ pT2, a total of 4246 patients from the cohort would have been eligible to receive perioperative chemotherapy. Over the study period, there was a significant increase in utilization of perioperative chemotherapy from $19.0 \%$ in the earliest era to $35.2 \%$ in the most recent $(\mathrm{p}<0.001)$. Patient referral to medical oncology pre-operatively increased from $12.1 \%$ to $31.5 \%(\mathrm{p}<0.001)$ with similar increasing trends for post-operative referrals (Supplementary Figure 1). In alignment with modern guidelines, the use of neoadjuvant chemotherapy increased substantially from $4.4 \%$ in $1994-2008$ to $18.7 \%$ in $2009-2013$ $(p<0.001)$. Patients in the contemporary period were more likely to have had a pre-operative referral to radiation oncology (data not shown).

A significant increase over time in the performance of PLND $(\mathrm{P}<0.001)$ was observed (Supplementary Figure 2). An explicit node count was available in 3544 of the 4246 PLND cases and of these cases 1135 had positive nodes. Median node counts significantly increased $(\mathrm{p}<0.001)$ over time with a subsequent decrease in median node density per year $(\mathrm{p}<0.001)$. The margin positive rate was variable over the years from $6.6 \%$ to $19.6 \%$ without any significant trends over the study period. The utilization of continent urinary diversions appears to have significantly increased over the study period from $10.9 \%$ in the first era to $13.5 \%$ in $2009-2013$ $(\mathrm{p}<0.001)$.

There did not appear to be any substantive change in distance travelled to surgical care with the mean ( \pm standard deviation) in the earliest era $41 \mathrm{~km}( \pm 84)$ compared to $46( \pm 92)(\mathrm{p}=$ $0.250)$ in the contemporary era. As centralisation of care could potentially translate to longer wait times, both for intervening diagnostic tests and resulting greater work-loads of higher volume providers, we assessed the wait times over the study period and indeed there appeared to be an associated increase over the four study periods and the proportion of patients receiving $\mathrm{RC}$ within 3 months from initial diagnosis decreased from $57 \%$ in the first era to $47 \%$ in the most recent $(\mathrm{p}<0.001$, Supplementary Table 1$)$.

Centralisation of RC to higher volume providers was associated with a trend to an effect on re-admission rates at $30-(\mathrm{p}=0.003)$ and 90 -days $(\mathrm{p}=0.087)$. In adjusted analyses there was no evidence of any change on 30- or 90-day mortality. There was however a significant improvement in CSS and overall survival (OS) over the study period (depicted in Figure 2) [Adjusted CSS HR 0.60 (95\% CI 0.53-0.67), OS HR 0.80 (95\% CI 0.73-0.89) in 2009-2013]. When assessing survival adjusting for age, comorbidity, LVI, T stage, N stage, and adjuvant chemotherapy (excluding neoadjuvant chemotherapy cases as stage would be confounded) we still demonstrated an effect on CSS over time with a HR of 0.73 (95\% CI 0.64-0.84) in 20092013.

Despite demonstrating some degree of centralisation in the later years of the study, there were still a significant number of lower volume providers. The maximum number of annual cases for the lowest quartile (Q1) surgeons was 1.8 cases compared to 19.2 for the highest quartile (Q4). Similar discrepancies were seen for hospital volume with 6.4 cases for Q1 and 32.2 for Q4. During this most recent era there was still evidence of a surgeon volume effect on 
RC process measures, including quality of PLND and utilization of NACT (Table 2). In adjusted analysis there was a demonstrable association with surgeon volume and post-operative mortality at 90 days $\mathrm{OR}=0.60$ (95\% CI 0.36-0.99) although no effect on readmission rates were identified (Supplementary Table 2A). Survival analysis by surgeon volume, adjusted for age and comorbidity, demonstrated an association with CSS, HR for Q4 was 0.82 (95\% CI 0.65-1.02), although the trend for OS was not significant (Supplementary Table 2B). Adjusting for pathological variables (excluding those that received NACT) the significant volume effect on CSS was maintained: HR for Q4 0.83 (95\% CI 0.65-1.06). Similar trends were seen for hospital provider volumes.

\section{Discussion}

In this study we demonstrate passive centralisation of RC in Ontario with a substantial shift in practice to higher volume providers. Despite the lack of mandated consolidation of surgical care for bladder cancer, herein we have demonstrated a number of resulting associations with the delivery of care for these patients and their outcomes. First, over the study period, there have been substantial improvements in a number of process-related quality indicators including consultation with multi-disciplinary teams, utilization of perioperative chemotherapy and enhanced pelvic lymph node dissections. Second, we have observed some evidence of improved early outcomes over time, including a decrease in re-admission rates. Third, over the study period we have seen a substantial improvement in CSS. Finally, despite demonstrating some degree of centralization across the province, there was still a significant number of lower volume providers with a persistent association of the provider volume effect on process-related factors as well as outcomes.

The relationship between higher provider volumes and improved outcomes has been well described in many surgical disciplines, including RC for bladder cancer ${ }^{(2,5,9)}$. Survival of patients with MIBC in these higher volume, cancer-focused centers have consistently been higher ${ }^{(18)}$ than those reports from population-level studies of routine clinical care (30-43\%) $(2,18,19)$ Although some of this discrepancy may be due to case mix or variations in data capture, it is likely that these improved outcomes follow Donebedian's framework of health quality where excellent structures lead to optimized processes-of-care. ${ }^{(20)}$ These processes reflect various perioperative factors such as patient selection, adherence to care pathways as well as technical proficiencies and indeed Hollenbeck et al. ${ }^{(21)}$ demonstrated a number of processes of these factors that may explain some of the volume effect on early mortality in RC. Similarly, we have previously presented models suggesting that the volume effect on CSS was modestly mediated by the quality of PLND and utilization of perioperative chemotherapy ${ }^{(2)}$. In 2015, leaders from three prominent US-based hospital systems publicly announced a "Take the Volume Pledge" to advocate restraint for certain surgical procedures being done by lower volume providers and set minimum volume standards for a number of elective surgical procedures ${ }^{(22)}$. There has been some experience of mandated centralization of surgical oncology in Canada and throughout Europe. In urological oncology, the Martini Clinic has centralized 
radical prostatectomy, performing more than 2000 cases per year with documented superior oncologic and functional outcomes when compared to other hospitals ${ }^{(23)}$. A recent report of RC provides evidence that the creation of a centralized high-volume center and concurrent quality program can lead to improvements in outcome within a short period of time ${ }^{(24)}$.

Although based on the strong volumes-outcomes literature, reactions to campaigns of regionalization have not been completely positive with concerns around its scientific underpinnings including case mix leading to selection bias for higher volume providers, issues around patient/surgeon autonomy and choice, as well as the logistic issues around moving certain procedures and subsequent personnel to different hospitals. Others worry centralization may create access problems for a substantial proportion of patients in the population and worsen existing disparities between those in rural communities/treated at lower volume centers ${ }^{(25-27)}$. One recent study by Casey et al describe a complicated relationship between centralization and access in New York State ${ }^{(28)}$ although in this present study we did not identify any strong signal of access issues during the observed passive centralization in Ontario. We did observe an increase in wait times from diagnosis to $\mathrm{RC}$ in the most recent era in Ontario although these data are limited by the management details prior to the $\mathrm{RC}$ and may be confounded by other recent resource constraints. Finally, there is little current literature, specifically in RC for bladder cancer, benchmarking provider volumes and exploring the presence of any ceiling effect of centralization. In the meantime, some patients will continue to require oncological surgery at medium-sized hospitals and care for these patients can only improve if other structures- and processes-of care can be widely adopted.

Overall, these results do confirm some degree of passive centralization of $\mathrm{RC}$, likely driven by the increasing importance of multi-disciplinary care for MIBC, understanding of the volume-outcome paradigm for RC and perhaps by the marketplace. This centralization was associated with improved processes-of-care, as well as early and late outcomes. Although unable to confirm a direct cause and effect relationship, our analysis in the most recent years of the study again confirm a strong, ongoing relationship with both surgeon and hospital volume and key processes-of-care suggesting that gains made in outcomes of patients after RC are likely secondary to more optimal care by higher volume providers. However, as this consolidation of care has not been mandated it remains incomplete with evidence of ongoing provision of RC by very low volume surgeons and hospitals. About half of the patients were treated by surgeons performing less than 3.6 cases per year in Ontario between 2009-2013.

This study's strength includes the large number of cases, removing selection bias by capturing all cases of bladder cancer treated with RC and therefore reflective of the Ontario population. However, our data has some limitations most importantly those inherent in retrospective, observational studies. Although this dataset does include general information regarding disease state, treatments obtained and related outcomes it does lack patient specific details such as specific individual pre-operative risk, imaging data, and patient preferences.

\section{Conclusions}


This study documents passive centralization of $\mathrm{RC}$ to higher-volume providers in the province of Ontario. Associated with this centralization, there has been measurable improvements in processes-related indicators of quality surgical care, including utilization of the multidisciplinary team. Although there was also an associated improvement in cancer-specific survival, in the most recent era there was continued evidence of low volume providers in Ontario with a remaining volume effect on processes of care and outcomes._Continuing to promote centralization of RC would appear to be appropriate, along with advocacy of quality program implementation and benchmarking of both structure- and process-related indicators of care. 


\section{References}

1. Finks, Jonathan F., Nicholas H. Osborne, and John D. Birkmeyer. "Trends in hospital volume and operative mortality for high-risk surgery." New England Journal of Medicine 364.22 (2011): 2128-2137.

2. Siemens DR, Mackillop WJ, Peng Y, et al. Processes of care and the impact of surgical volumes on cancer-specific survival: a population-based study in bladder cancer. Urology. 2014 Nov 1;84(5):1049-57.

3. Christian CK, Gustafson ML, Betensky RA, et al. The volume outcome relationship: don't believe everything you see. World J Surg. 2005;29:1241-1244.

4. National Research Council. Interpreting the volume-outcome relationship in the context of cancer care. National Academies Press; 2001 Aug 11.

5. Afshar, Mehran, et al. "Centralisation of radical cystectomies for bladder cancer in England, a decade on from the 'Improving Outcomes Guidance': the case for super centralisation." BJU international 121.2 (2018): 217-224.

6. Finley, Christian J., et al. "The effect of regionalization on outcome in pulmonary lobectomy: a Canadian national study." The Journal of thoracic and cardiovascular surgery 140.4 (2010): 757-763.

7. Stitzenberg, Karyn B., et al. "Centralization of cancer surgery: implications for patient access to optimal care." Journal of Clinical Oncology 27.28 (2009): 4671.

8. Fong ZV, Loehrer AP, Fernández-del Castillo C, et al. Potential impact of a volume pledge on spatial access: A population-level analysis of patients undergoing pancreatectomy. Surgery. 2017 Aug 1;162(2):203-10.

9. Konety BR, Dhawan V, Allareddy V, Joslyn SA. Impact of hospital and surgeon volume on in-hospital mortality from radical cystectomy: data from the health care utilization project. The Journal of urology. 2005 May 1;173(5):1695-700.

10. Herr H, Lee C, Chang SA, Lerner S, Bladder Cancer Collaborative Group. Standardization of radical cystectomy and pelvic lymph node dissection for bladder cancer: a collaborative group report. The Journal of Urology. 2004 May 1;171(5):1823-8.

11. Herr HW. Extent of surgery and pathology evaluation has an impact on bladder cancer outcomes after radical cystectomy. Urology. 2003 Jan 1;61(1):105-8.

12. Kassouf W, Aprikian A, Black P, et al. Recommendations for the improvement of bladder cancer quality of care in Canada: A consensus document reviewed and endorsed by Bladder Cancer Canada (BCC), Canadian Urologic Oncology Group (CUOG), and Canadian Urological Association (CUA), December 2015. Canadian Urological Association Journal. 2016 Jan;10(1-2):E46.

13. Booth CM, Siemens DR, Li G, et al. Perioperative chemotherapy for muscle-invasive bladder cancer: A population-based outcomes study. Cancer. 2014 Jun 1;120(11):1630-8.

14. Clarke EA, Marrett LD, Kreiger N. Appendix 3 (c) Cancer registration in Ontario: a computer approach. Cancer Registration Principles and Methods. Lyon: IARC Publications. 1991:246-57.

15. Williams JI, Young W. A summary of studies on the quality of health care administrative databases in Canada. Patterns of health care in Ontario: the ICES practice atlas. 2nd ed. Ottawa: Canadian Medical Association. 1996;339:45. 
16. Booth CM, Li G, Zhang-Salomons J, Mackillop WJ. The impact of socioeconomic status on stage of cancer at diagnosis and survival: a population-based study in Ontario, Canada. Cancer. 2010 Sep 1;116(17):4160-7.

17. Von Elm E, Altman DG, Egger M, et al, Strobe Initiative. The Strengthening the Reporting of Observational Studies in Epidemiology (STROBE) statement: guidelines for reporting observational studies. PLoS medicine. 2007 Oct 16;4(10):e296.

18. Yafi FA, Aprikian AG, Chin JL, et al. Contemporary outcomes of 2287 patients with bladder cancer who were treated with radical cystectomy: a Canadian multicentre experience. BJU international. 2011 Aug 1;108(4):539-45.

19. Kulkarni GS, Urbach DR, Austin PC, Fleshner NE, Laupacis A. Higher surgeon and hospital volume improves long-term survival after radical cystectomy. Cancer. 2013 Oct 1;119(19):3546-54.

20. Donabedian A. Evaluating the quality of medical care. The Milbank Quarterly. 2005 Dec;83(4):691-729.

21. Hollenbeck BK, Wei Y, Birkmeyer JD. Volume, process of care, and operative mortality for cystectomy for bladder cancer. Urology. 2007 May 1;69(5):871-5

22. Urbach DR. Pledging to eliminate low-volume surgery. New England Journal of Medicine. 2015 Oct 8;373(15):1388-90.

23. Schlomm T, Huland H, Graefen M. Improving outcome of surgical procedures is not possible without adequate quality measurement. European Urology. 2014 Jun 1;65(6):1017-9.

24. Cathcart P, Sridhara A, Ramachandran N, et al. Achieving quality assurance of prostate cancer surgery during reorganization of cancer services. European urology. $2015 \mathrm{Jul}$ $1 ; 68(1): 22-9$

25. Liu JH, Zingmond DS, McGory ML, et al. Disparities in the utilization of high-volume hospitals for complex surgery. Jama. 2006 Oct 25;296(16):1973-80.

26. Ward MM, Jaana M, Wakefield DS, et al. What would be the effect of referral to highvolume hospitals in a largely rural state?. The Journal of Rural Health. 2004 Sep;20(4):34454.

27. Birkmeyer JD, Siewers AE, Marth NJ, Goodman DC. Regionalization of high-risk surgery and implications for patient travel times. Jama. 2003 Nov 26;290(20):2703-8.

28. Casey MF, Wisnivesky J, Le VH, et al. The relationship between centralization of care and geographic barriers to cystectomy for bladder cancer. Bladder Cancer. 2016 Jan 1;2(3):31927.

Figures and Tables 
Fig. 1. (A) Median annual surgeon and hospital volume across the study years. (B) Proportion of cases per year high volume surgeon $(>6.2)$ and for high-volume hospital $(>20)$.

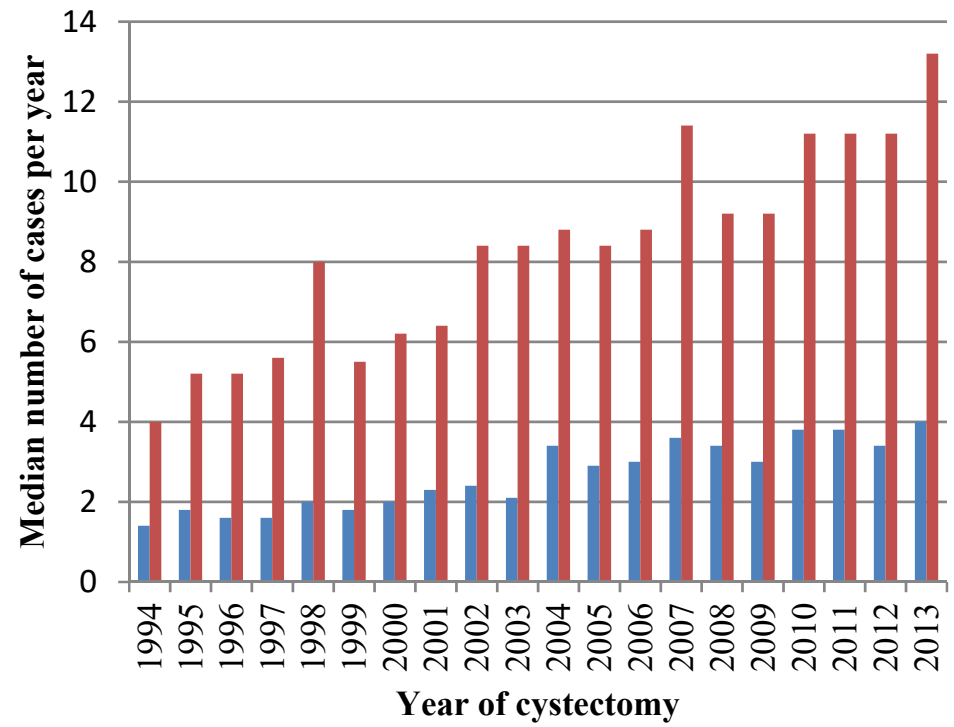

- Surgeon Volume

Hospital Volume

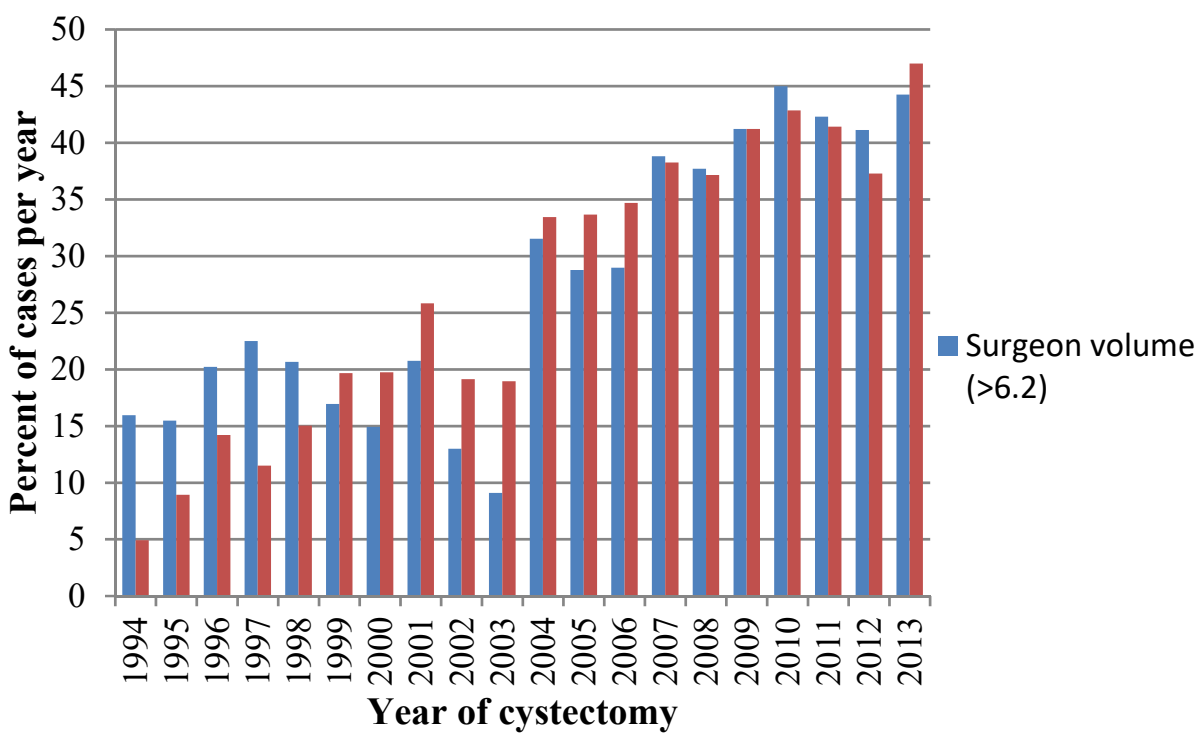


Fig. 2. Proportion of patients with muscle-invasive bladder cancer treated with cystectomy in Ontario from 1994-2013 seen by medical oncology (MO) in the (A) preoperative and (B) postoperative settings, and subsequent use of neoadjuvant (NACT) and adjuvant chemotherapy (ACT) among these patients.

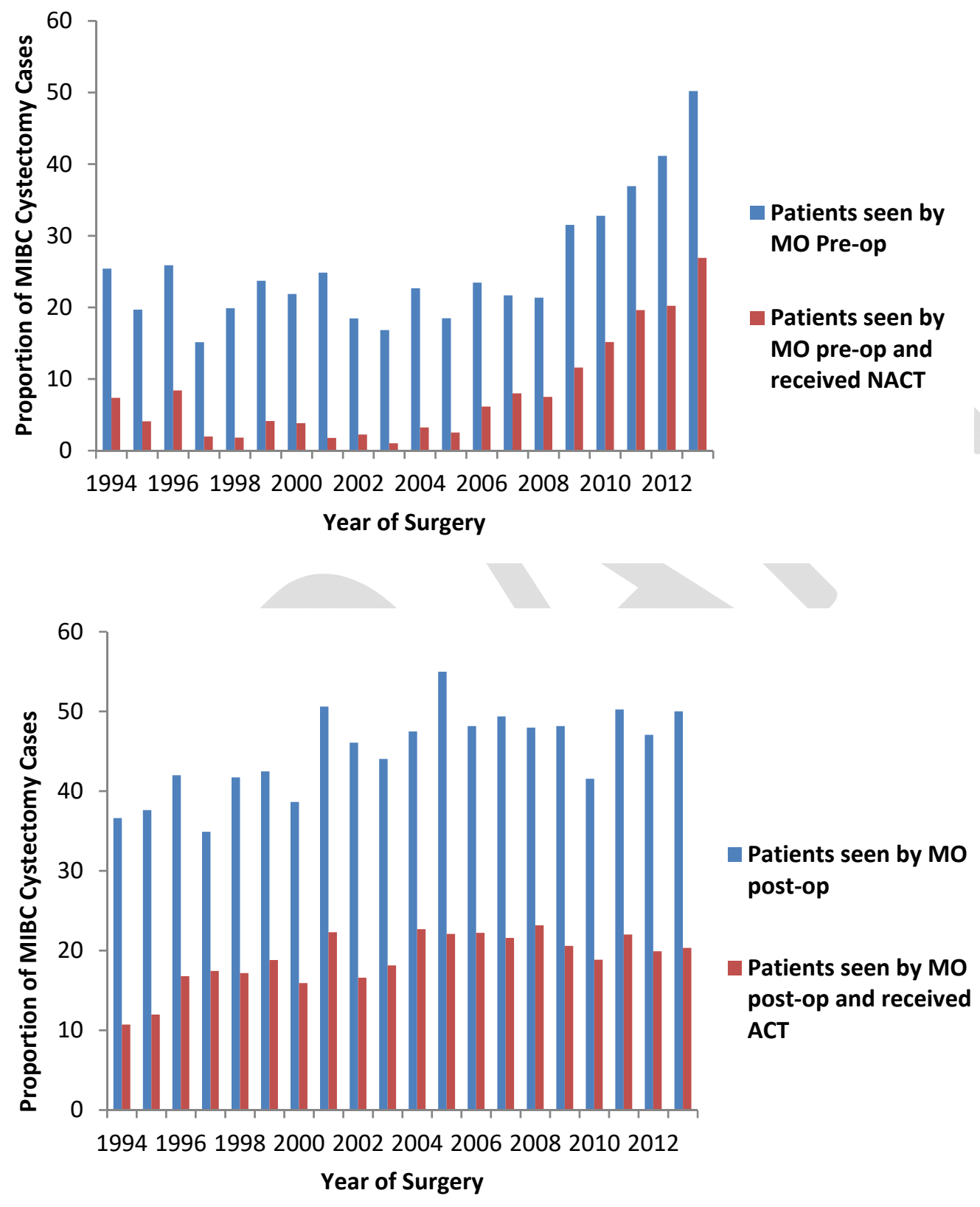


Fig. 3. Survival curves for all bladder cancer cases. (A) Cancer-specific survival; (B) overall survival.
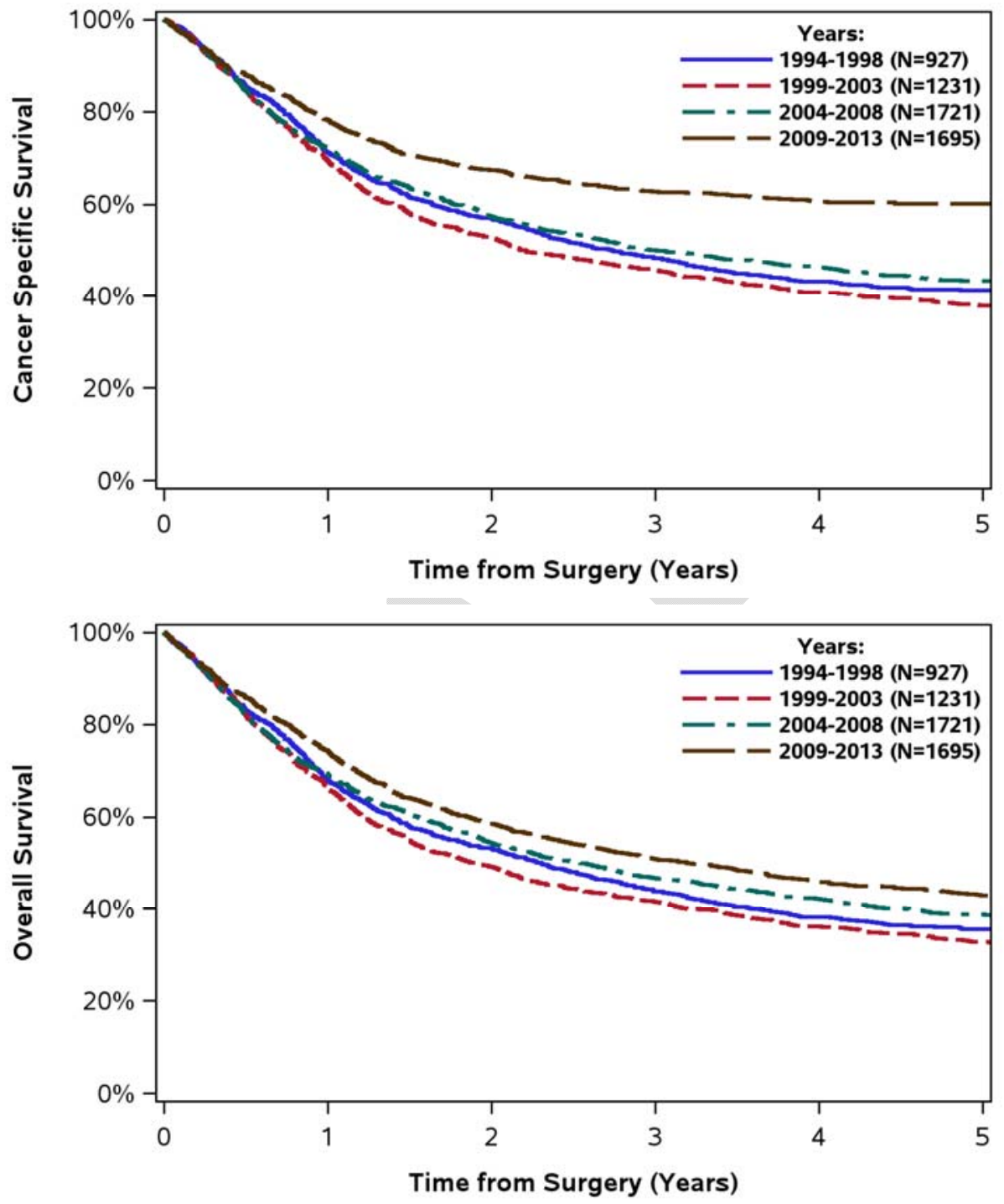


\begin{tabular}{|c|c|}
\hline & $\begin{array}{c}(n=5574) \\
n(\%)\end{array}$ \\
\hline \multicolumn{2}{|l|}{ Patient-related } \\
\hline \multicolumn{2}{|l|}{ Year of surgery } \\
\hline 1994-1998 & $927(17 \%)$ \\
\hline 1999-2003 & $1231(22 \%)$ \\
\hline $2004-2008$ & $1721(31 \%)$ \\
\hline $2009-2013$ & $1695(30 \%)$ \\
\hline \multicolumn{2}{|l|}{ Age $(\text { years })^{1}$} \\
\hline $20-49$ & $213(4 \%)$ \\
\hline $50-59$ & $699(13 \%)$ \\
\hline $60-69$ & $1469(26 \%)$ \\
\hline $70-79$ & $2134(38 \%)$ \\
\hline $80+$ & $1059(19 \%)$ \\
\hline \multicolumn{2}{|l|}{ Sex } \\
\hline Male & $4182(75 \%)$ \\
\hline Female & $1392(25 \%)$ \\
\hline \multicolumn{2}{|l|}{ SES by quintile $^{2}$} \\
\hline 1 & $1098(20 \%)$ \\
\hline 2 & $1244(22 \%)$ \\
\hline 3 & $1206(22 \%)$ \\
\hline 4 & $1042(19 \%)$ \\
\hline 5 & $931(17 \%)$ \\
\hline Unknown & $53(1 \%)$ \\
\hline \multicolumn{2}{|l|}{ Comorbidity score } \\
\hline 0 & $3856(69 \%)$ \\
\hline $1+$ & $1718(31 \%)$ \\
\hline \multicolumn{2}{|l|}{ Disease-related } \\
\hline \multicolumn{2}{|l|}{ Pathologic T stage } \\
\hline$<\mathrm{T} 2$ & $1058(19 \%)$ \\
\hline $\mathrm{T} 2$ & $1272(23 \%)$ \\
\hline T3 & $2107(38 \%)$ \\
\hline $\mathrm{T} 4$ & $1121(20 \%)$ \\
\hline $\mathrm{TX}$ & $16(0 \%)$ \\
\hline
\end{tabular}




\begin{tabular}{|c|c|}
\hline Pathologic N stage & \\
\hline N negative & $3102(56 \%)$ \\
\hline N positive & $1377(25 \%)$ \\
\hline NX & $1095(20 \%)$ \\
\hline LVI & \\
\hline No & $1509(27 \%)$ \\
\hline Yes & $2186(39 \%)$ \\
\hline Unstated & $1879(34 \%)$ \\
\hline
\end{tabular}

${ }^{1}$ Age is based on date of cystectomy. ${ }^{2}$ Socioeconomic status, quintile 1 represents communities where the poorest $20 \%$ of the Ontario population resided.SES: socioeconomic status; LVI: lymphovascular invasion.

\begin{tabular}{|c|c|c|c|c|c|}
\hline & \multicolumn{2}{|c|}{ Surgeon volume } & \multicolumn{2}{|c|}{ 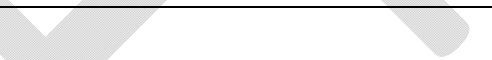 } & \multirow[t]{2}{*}{$\mathbf{p}$} \\
\hline & $\begin{array}{l}\text { Q1 (low } \\
\text { volume) }\end{array}$ & Q2 & Q3 & $\begin{array}{l}\text { Q4 (high } \\
\text { volume) }\end{array}$ & \\
\hline $\begin{array}{l}\text { Preoperative MO } \\
\text { referral }^{\wedge}\end{array}$ & $102(23 \%)$ & $122(30 \%)$ & $121(27 \%)$ & $116(29 \%)$ & 0.141 \\
\hline $\begin{array}{l}\text { Preoperative MO } \\
\text { referral }^{*}\end{array}$ & $95(28 \%)$ & $112(34 \%)$ & $104(31 \%)$ & $99(35 \%)$ & 0.224 \\
\hline $\begin{array}{l}\text { Preoperative RO } \\
\text { referral }^{\wedge}\end{array}$ & $44(10 \%)$ & $50(12 \%)$ & $93(21 \%)$ & $46(11 \%)$ & $<0.001$ \\
\hline PLND yes $^{\wedge}$ & $396(90 \%)$ & $364(89 \%)$ & $430(97 \%)$ & $398(99 \%)$ & $<0.001$ \\
\hline $\begin{array}{l}\text { Median node count } \\
\text { (IQR) }\end{array}$ & $9(5-15)$ & $10(6-15)$ & $11(7-18)$ & $15(9-21)$ & $<0.001$ \\
\hline Mean node density & $0.34 \pm 0.27$ & $0.31 \pm 0.25$ & $0.28 \pm 0.26$ & $0.26 \pm 0.25$ & 0.096 \\
\hline Margin status & & & & & 0.685 \\
\hline Any positive & $83(19 \%)$ & $71(17 \%)$ & $89(20 \%)$ & $71(18 \%)$ & \\
\hline All negative & $349(79 \%)$ & $331(81 \%)$ & $351(79 \%)$ & $330(82 \%)$ & \\
\hline Unstated & $7(2 \%)$ & $6(1 \%)$ & $\leq 5(1 \%)$ & $\leq 5(1 \%)$ & \\
\hline NACT rate ${ }^{*}$ & $56(16 \%)$ & $63(19 \%)$ & $52(15 \%)$ & $72(25 \%)$ & 0.009 \\
\hline ACT rate & $60(17 \%)$ & $77(23 \%)$ & $63(19 \%)$ & $55(19 \%)$ & 0.283 \\
\hline
\end{tabular}

^Among all surgical cases 2009-2013. "Among those with PLND yes. *Among MIBC cohort 2009-2013. ACT: adjuvant chemotherapy; IQR: interquartile range; MO: medical oncologist; NACT: neoadjuvant chemotherapy; RO: radiation oncologist; PLND: pelvic lymph node dissection. 
Supplementary Fig. 1. Temporal trend in quality of pelvic lymph node dissection

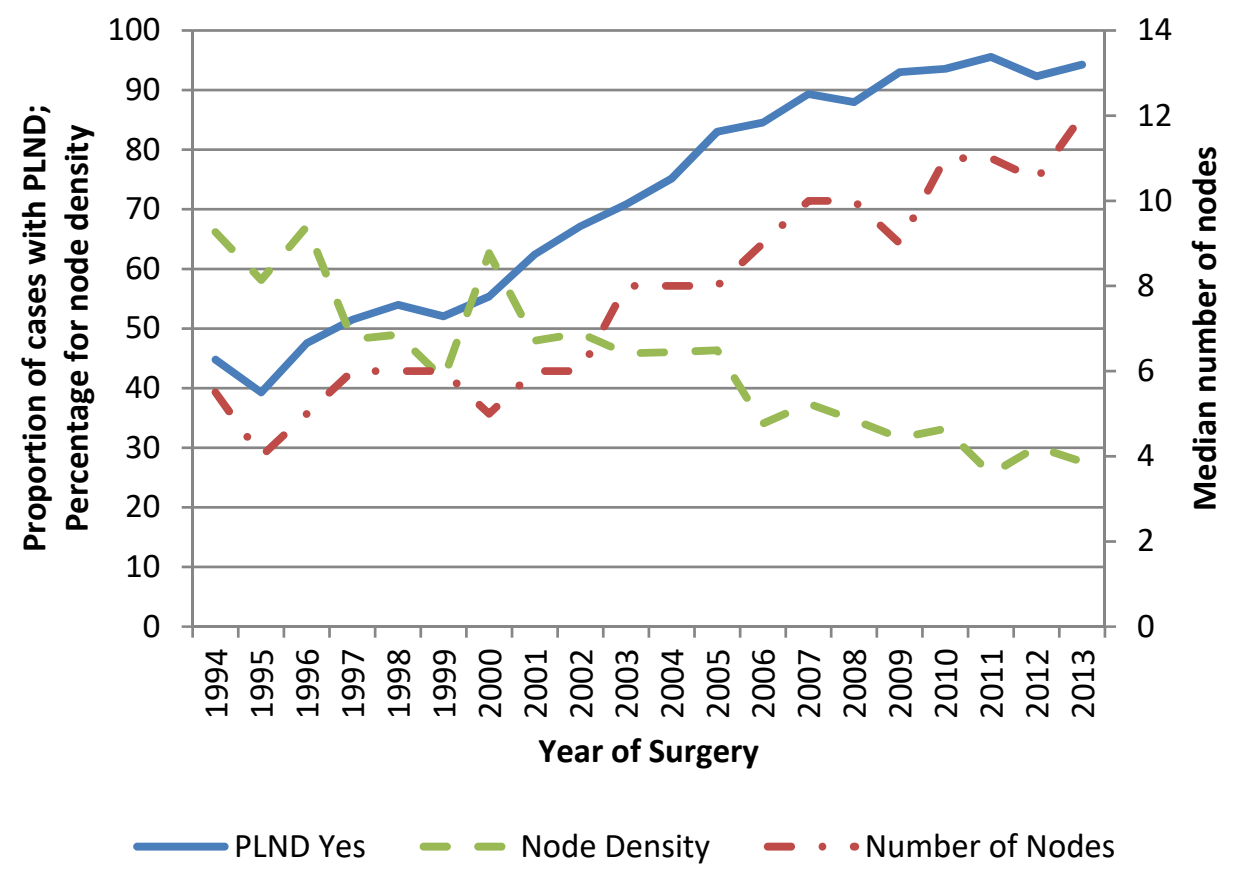




\begin{tabular}{|c|c|c|c|c|c|c|}
\hline \multicolumn{7}{|c|}{$\begin{array}{l}\text { Supplementary Table 1. Interval from diagnosis to surgery and distance travelled for care } \\
\text { by over study period }\end{array}$} \\
\hline \multirow[t]{2}{*}{ Variable } & Value & 1994-1998 & 1999-2003 & $2004-2008$ & $2009-2013$ & $\mathrm{p}$ \\
\hline & & $\mathrm{n}=927$ & $\mathrm{n}=1231$ & $\mathrm{n}=1721$ & $n=1695$ & \\
\hline \multirow{8}{*}{$\begin{array}{l}\text { Interval } \\
\text { from } \\
\text { diagnosis to } \\
\text { date of } \\
\text { cystectomy, } \\
\text { months }\end{array}$} & Mean \pm SD & $13.58 \pm 25.95$ & $15.08 \pm 30.83$ & $17.32 \pm 35.20$ & $13.84 \pm 32.65$ & 0.005 \\
\hline & $\begin{array}{l}\text { Median } \\
\text { (IQR) }\end{array}$ & $3(1-12)$ & $3(1-13)$ & $3(1-13)$ & $4(2-9)$ & $<0.001$ \\
\hline & 1-3 months & $531(57 \%)$ & $664(54 \%)$ & $884(51 \%)$ & $794(47 \%)$ & $<0.001$ \\
\hline & 4-6 months & $103(11 \%)$ & $147(12 \%)$ & $218(13 \%)$ & $346(20 \%)$ & \\
\hline & $\begin{array}{c}7-12 \\
\text { months }\end{array}$ & $65(7 \%)$ & $110(9 \%)$ & $176(10 \%)$ & $198(12 \%)$ & \\
\hline & $\begin{array}{c}13-24 \\
\text { months }\end{array}$ & $81(9 \%)$ & $108(9 \%)$ & $134(8 \%)$ & $140(8 \%)$ & \\
\hline & $>24$ months & $147(16 \%)$ & $202(16 \%)$ & $309(18 \%)$ & $217(13 \%)$ & \\
\hline & & & & & & \\
\hline \multirow{7}{*}{$\begin{array}{l}\text { Distance } \\
\text { from home } \\
\text { to surgical } \\
\text { hospital, km }\end{array}$} & Mean $\pm \mathrm{SD}$ & $40.75 \pm 84.33$ & $40.24 \pm 86.58$ & $45.64 \pm 99.97$ & $45.59 \pm 92.19$ & 0.248 \\
\hline & $\begin{array}{l}\text { Median } \\
\text { (IQR) }\end{array}$ & $9(4-37)$ & $11(4-38)$ & $13(5-45)$ & $14(5-45)$ & $<0.001$ \\
\hline & $0-50 \mathrm{~km}$ & $743(80 \%)$ & $987(80 \%)$ & $1337(78 \%)$ & $1324(78 \%)$ & 0.15 \\
\hline & $51-100 \mathrm{~km}$ & $96(10 \%)$ & $133(11 \%)$ & $221(13 \%)$ & $204(12 \%)$ & \\
\hline & $101-200 \mathrm{~km}$ & $47(5 \%)$ & $66(5 \%)$ & $94(5 \%)$ & $93(5 \%)$ & \\
\hline & $201-300 \mathrm{~km}$ & $6(1 \%)$ & $10(1 \%)$ & $16(1 \%)$ & $29(2 \%)$ & \\
\hline & $>300 \mathrm{~km}$ & $35(4 \%)$ & $35(3 \%)$ & $53(3 \%)$ & $45(3 \%)$ & \\
\hline
\end{tabular}

IQR: interquartile range; SD: standard deviation.

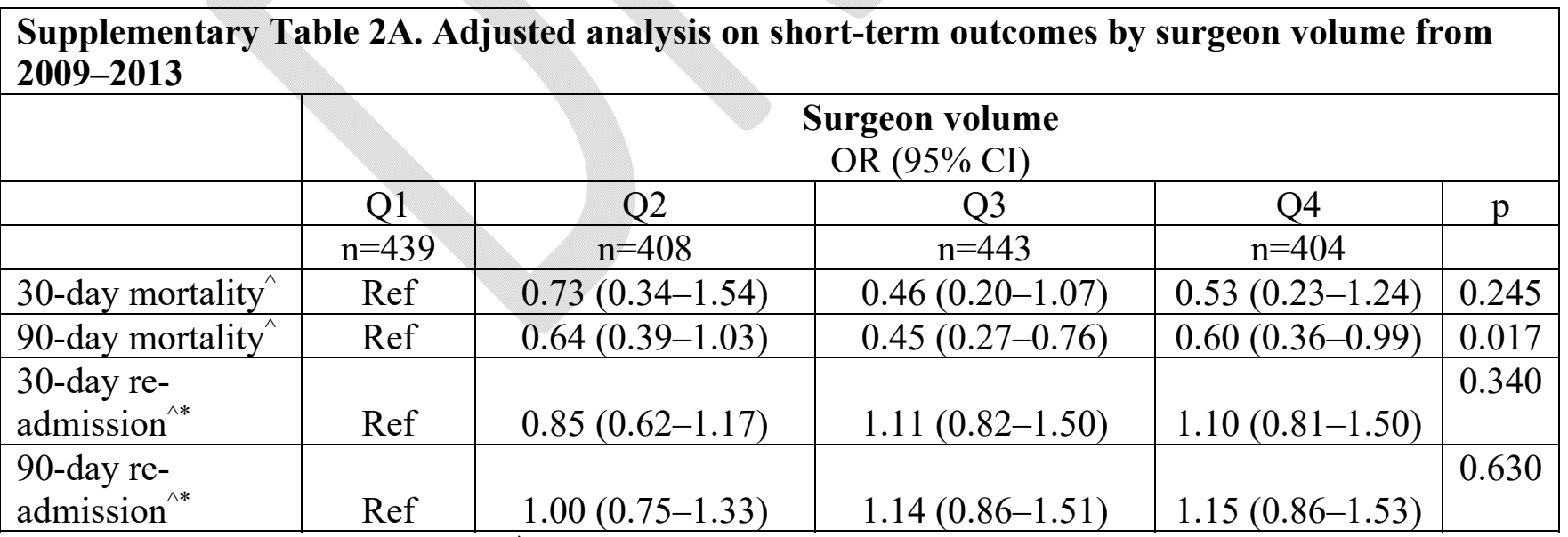

^Adjusted for age and comorbidity. *Numerator for hospital re-admission rate included cases discharged and re-admitted and those who died in hospital before discharge and cases never discharged at 30/90 days. Denominator included all cases. CI: confidence interval; OR: odds ratio. 


\begin{tabular}{|c|c|c|c|c|c|}
\hline \multicolumn{6}{|c|}{$\begin{array}{l}\text { Supplementary Table 2B. Adjusted analysis on survival outcome by surgeon volume from } \\
2009-2013\end{array}$} \\
\hline & \multicolumn{5}{|c|}{$\begin{array}{c}\text { Surgeon volume } \\
\mathrm{HR}(95 \% \mathrm{CI})\end{array}$} \\
\hline & Q1 & Q2 & Q3 & Q4 & $\mathbf{p}$ \\
\hline & $\mathrm{n}=439$ & $\mathrm{n}=408$ & $\mathrm{n}=443$ & $\mathrm{n}=404$ & \\
\hline $\mathrm{CSS}^{\wedge}$ & Ref & $0.83(0.67-1.04)$ & $0.71(0.57-0.89)$ & $0.82(0.65-1.02)$ & 0.023 \\
\hline$\overline{\mathrm{OS}^{\wedge}}$ & Ref & $0.95(0.79-1.13)$ & $0.83(0.70-1.00)$ & $0.83(0.69-0.99)$ & 0.100 \\
\hline
\end{tabular}

${ }^{\wedge}$ Adjusted for age and comorbidity. CI: confidence interval; CSS: cancer-specific survival; HR: hazard ratio; OS: overall survival. 